\title{
Research on the Influence of Distributed Generation on Voltage in Rural Distribution Network
}

\author{
Shen Zeyuan ${ }^{1 *}$, Song Wei ${ }^{1}$, Zhao Haibo ${ }^{1}$, Li Chunhui ${ }^{1}$, Shen Zebo ${ }^{2}$, Hu Ende ${ }^{1}$, Xing Yahong ${ }^{1}$, Wang Miao ${ }^{1}$ and Gao Wei ${ }^{1}$ \\ ${ }^{1}$ Economic and Technical Research Institute of SEPC of SGCC, Taiyuan, China \\ ${ }^{2}$ State Grid Changzhi Power Supply Company, Changzhi, China
}

\begin{abstract}
With the development of photovoltaic projects for poverty alleviation, large number of distributed photovoltaic power plant is incorporated rural grid. On the one hand, photovoltaic poverty project can increase the income of farmers, on the other hand, it can improve the low voltage problem of rural distribution network. While photovoltaic power plant incorporating makes the distribution network from traditional radial network become active network, and causes a change of voltage distribution in feeder. Rural grid distribution network is the weakest link in the entire grid. So that it is necessary to analyse the influence factors of voltage distribution and the interconnection principles of photovoltaic power station. In this paper, through the modeling and simulation of distributed photovoltaic access to rural distribution network, analyses the law of the capacity and access location of photovoltaic power integration in the distribution network, and summarizes the interconnection requirements of the photovoltaic power station. The results show that only reasonable and proper use the distributed photovoltaic power plant, can play the role of voltage support and solve the problem of low voltage in rural distribution network.
\end{abstract}

\section{Introduction}

Photovoltaic (PV) poverty alleviation project is a new approach to alleviating the problem of the poverty, which is useful in not only rural electric power supply and development of the infrastructure, but also achieving the new energy policy of China. With the development of the Photovoltaic poverty alleviation project, the innovation of rural power grids and micro grids, rural power grids encounter a great number of challenges. When the distributed photovoltaic power station is incorporated into the rural distribution network, the structure of the distribution network is changed from the traditional radial network into an active one, and the distribution feeder voltage also changes [1]. The right access of the PV can not only strengthen the reliability of the distribution network and ability of the voltage support, but also improve the effect of the load power factor. But the wrong access of the PV also can cause a great threat for the power system. With the further development of the Photovoltaic poverty alleviation project, the impact of the distributed PV on the voltage distribution in distribution networks is paid more attention to for carrying out the poverty alleviation project and innovation of the rural power grid [2].

The related work for the impact of the distributed PV on distribution networks is mainly focused on the $10 \mathrm{kV}$ and above voltage. In [3], the distributed PV is considered to be a load in distribution networks and the impact is simulated in an integrated circuit model including the generalized load. In [4], the voltage changes of different nodes in radial and linked distribution networks including distributed power sources are observed for the triangle load model, which is used to analyse the regulation effect of those power sources. In [5-7] the evolution mechanism of the voltage in the distribution network with the grid-connected photovoltaic generation is studied in terms of the capacity and location of a PV. In [8], the impact of different kinds of distributed generations in distribution networks on the index of static voltage stability is analysed. In [9], the voltage variation before and after incorporating the PV generation into distribution networks is observed from the viewpoint of the voltage drop. The influences of the single and multi PV generation are analysed respectively. In [10], based on the voltage deviation and fluctuation in the distribution network with the grid-connected photovoltaic generation, a judgment condition satisfied with the power quality without that automation control is proposed.

In the PV poverty alleviation project, the distributed PV generations are mainly linked into the $380 \mathrm{~V} / 220 \mathrm{~V}$ distribution feeders. But most of the feeders are located in poverty districts with the weaker infrastructure and the limited power capacity. The incompatible access to the distribution network for the distributed PV generation can give rise to many serious problems such as the overload and low power quality, which is a great threat for the residential daily life and safety of the power grid. In order to carry out the poverty alleviation project and innovation of the rural power grid, the further study for

a Corresponding author: szy33519@163.com 
the distributed PV generation linked into the $380 \mathrm{~V} / 220 \mathrm{~V}$ distribution feeders is proceeding now [11].

The paper focuses on the typical $\mathrm{T}$ access mode of the distributed PV and analyses the influence of the capacity, location and power factor of the PV on the rural low voltage distribution networks. The related model for $380 \mathrm{~V} / 220 \mathrm{~V}$ is applied to the pilot in the PV poverty alleviation project. The suggestions that derive from the influences of mentioned factors provide the important theory for the project.

\section{Typical access to $380 \mathrm{~V} / 220 \mathrm{~V}$ distribution networks for the distributed PV system}

The access mode of the distributed PV is identified by the power capacity of the distributed PV, cable capacity, upper transformer, capacity of the circuit and conditions of the given district, which aims at the safety of distribution networks with the grid-connected PV generation. As shown in Fig.1, The typical access mode of the distributed PV is composed of T access, dedicated access and the one of user demand side.

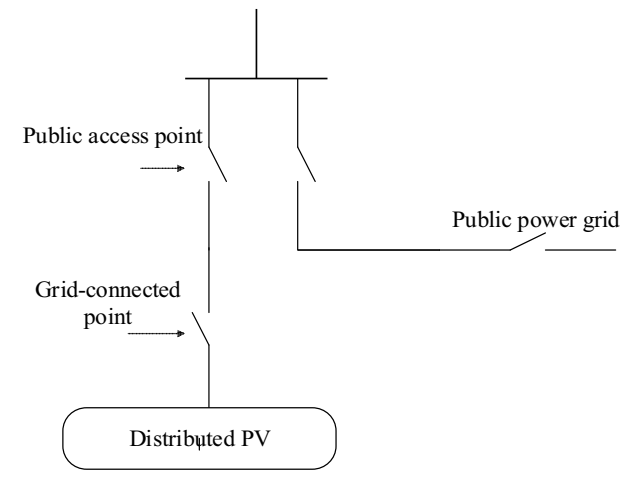

(a) Dedicated access

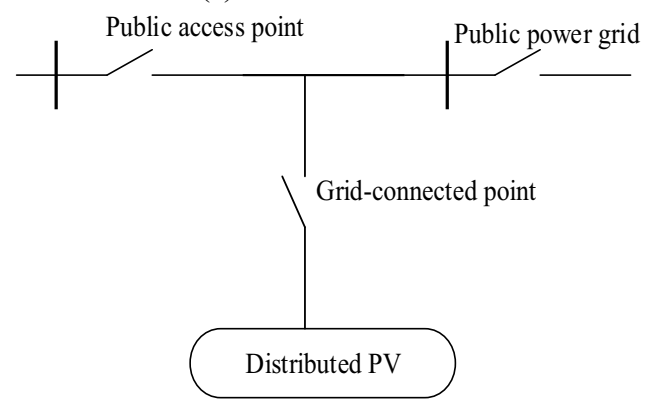

(b) $\mathrm{T}$ access

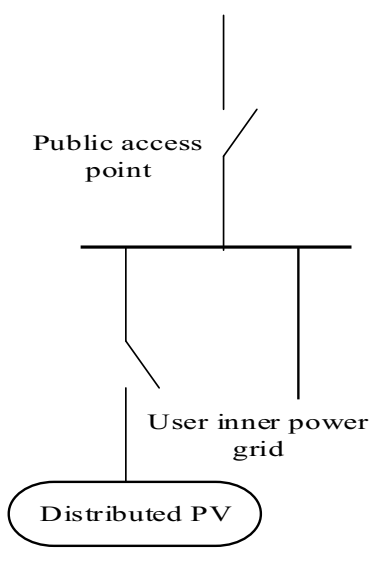

(c) User demand side access

Figure 1. Typical access to $380 \mathrm{~V} / 220 \mathrm{~V}$ distribution networks for of the distributed PV.

As for the dedicated access shown in Fig. 1(a), a switch equipment is allocated at the access point such as substations, opening and closing stations, the busbar of the distribution room and ring main unit. T access shown in Fig.1 (b) is opposite in comparison with the dedicated access. For example, there is no switch equipment such as an overhead line or cable branch box. The access of user demand side is linked into public grids through the user inner power grid, which is shown in Fig.1(c).

The differences among three access modes are shown in Table 1. The dedicated one is widely applied to substations, opening and closing stations, busbar of the distribution room, ring main unit and distributed PV with the high capacity. Although such a mode is simple, the price is very high. T access mode is widely applied to the distributed PV with the high capacity and dispersed connection. Although the price of the $\mathrm{T}$ access mode is low, the fault can easily influence the other parts of the distribution feeder. The one of user demand side is used in the distributed PV with the low capacity and offline operation. The obvious feature of such an access is low price. The paper lays emphasis on the $\mathrm{T}$ access, influences of the related capacity and access points on the voltage distribution.

Table 1. Typical characteristics of three access modes

\begin{tabular}{|c|c|c|c|}
\hline Mode & Dedicated access & T mode & $\begin{array}{c}\text { User demand } \\
\text { side }\end{array}$ \\
\hline $\begin{array}{c}\text { hequire capacity and } \\
\text { ment } \\
\text { close to substations, } \\
\text { opening and closing } \\
\text { stations, busbar of } \\
\text { the distribution } \\
\text { room, ring main unit }\end{array}$ & $\begin{array}{c}\text { high } \\
\text { capacity, } \\
\text { distributed } \\
\text { access }\end{array}$ & $\begin{array}{c}\text { Lowe } \\
\text { capacity, } \\
\text { single } \\
\text { generation }\end{array}$ \\
\hline $\begin{array}{c}\text { charact } \\
\text { eristic }\end{array}$ & $\begin{array}{c}\text { high cost, } \\
\text { low impact }\end{array}$ & $\begin{array}{c}\text { low cost, } \\
\text { high impact }\end{array}$ & $\begin{array}{c}\text { Low cost, } \\
\text { offline } \\
\text { operation }\end{array}$ \\
\hline
\end{tabular}




\section{Analysis on the impact of the distributed PV on the voltage profile in the form of $T$ access}

As mentioned above, the distributed PV can change the operation mechanism of the distribution networks. The paper constructs an equivalent circuit of the low voltage distribution network with the grid-connected distributed $\mathrm{PV}$ in the form of $\mathrm{T}$ access. And then the equations for evaluating the influence are presented from the capacity, access location and power factor respectively.

\subsection{Equivalent circuit of the distribution network with the grid-connected distributed PV in the form of $T$ access}

An equivalent circuit of the distribution network with the grid-connected distributed PV in the form of T access is shown in Fig.2. If the system voltage remains invariant, all nodes above the substation in Fig. 2 are considered voltage sources. There are different kinds of power loads in rural distribution networks. It is hard to describe the load because of the greater randomness and the load related to the given node in distribution lines is presented by a constant power static model. In Fig.2, $S_{S}, S_{D G}$ and $S_{L}$ denotes system capacity, access capacity of the PV and power load respectively. $\dot{U}_{S}, \dot{U}_{D G}$ and $\dot{U}_{L}$ denotes system busbar voltage, voltage of the access point of the distributed PV and the one of the load side respectively. $Z_{1}$ denotes the equivalent impedance between the access point and system busbar, and $Z_{2}$ denotes the one between the system busbar and load side. $\dot{I}_{1}, \dot{I}_{2}$ and $\dot{I}_{3}$ denotes the branch currents. The low capacity, high power factor and limited reactive power is the characteristics of the distributed PV mentioned in the paper, and the PV is considered to be a PQ node.

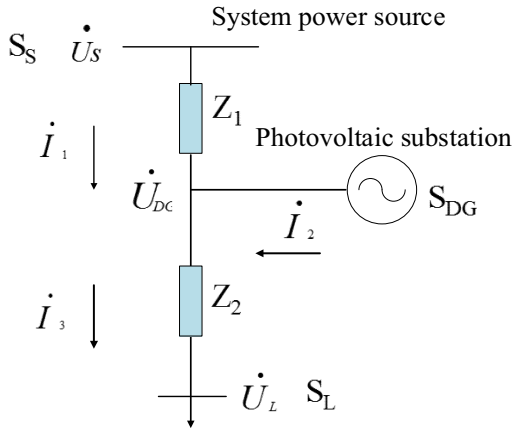

Figure 2. Equivalent circuit of the distributed photovoltaic in rural distribution networks

\subsection{Model of the influence of the distributed PV on the voltage profile of the distribution network in the form of $T$ access}

As for the distribution network with the grid-connected distributed PV, the PV causes a great impact on the access point in the distribution network and the voltage changes of those points are analysed. When a PV is linked into the distribution network, the variant of currents $d \dot{I}$ [12] derives from the power changes of the PV. As shown in Fig.2, the voltage variant in an access point is defined as following: The text of your paper should be formatted as follows:

$$
\begin{gathered}
d \dot{U}=Z 1 d \dot{I}=|Z 1|(\cos \phi+j \sin \phi)|d \dot{I}|(\cos \theta+j \sin \theta) \\
d I=\frac{\Delta S_{D G}}{U_{D G}} \\
d \dot{U}=\dot{U}_{D G}-\dot{U}_{0}
\end{gathered}
$$

Based on the Equations 1 and 3, the following equation is defined[13]:

$\mathrm{U}_{D G}=\frac{U_{0}}{2}+\left|Z_{1}\right| \Delta S_{D G} \times \frac{\sqrt{(\cos \phi \cos \theta-\sin \phi \sin \theta)+j(\sin \phi \cos \theta+\cos \phi \sin \theta)}}{2}$

which, $\Delta S_{D G}$ denotes the injection power of the distributed $\mathrm{PV}, \dot{U}_{0}$ denotes the voltage without the distributed PV, $\dot{U}_{D G}$ denotes the voltage with the gridconnected PV, $\theta$ denotes the power factor angle of the

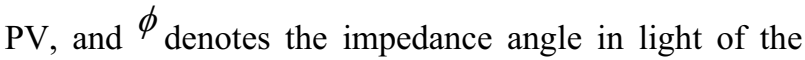
access point of the PV.

The phase shift is often small, and the transverse component is ignored. Hence, Eq. 1 can be simplified as followings:

$$
\Delta U=Z_{1} \Delta I=\left|Z_{1}\right||\Delta I| \cos (\phi+\theta)
$$

which, $\Delta U$ denotes the Longitudinal component, and Eq. 4 can be changed into the following format:

$$
U_{D G}=\frac{U_{0}+\sqrt{4\left|Z_{1}\right| \Delta S_{D G} \cos (\phi+\theta)}}{2}
$$

According to Eq. 6, the voltage distribution in distribution feeders can be changed by connecting the distributed PV and the voltage is raised. The voltage is related to the access capacity $\Delta S_{D G}$, power factor $\theta$ and access location $Z_{1}$.

\section{Experiment and results analysis}

The influence on the system voltage in the distribution network with the grid-connected PV is related to the access capacity, power factor and access location. The paper chooses a practical example from PV poverty alleviation project to validate and analyse the proposed method.

\subsection{Description of the practical example}

The experimental data are from the PV substation located in a village. There are 356 families and 1090 residents in the village. The power supply is reliable for all families and total load is $120 \mathrm{~kW}$. The equivalent circuit model is shown in Fig.3. The circuit is composed of the $10 \mathrm{kV} / 380 \mathrm{~V}$ transformer whose capacity is $200 \mathrm{Kva}$, $20 \mathrm{kVar}$ reactive power compensator, distributed PV which connects the outgoing line for the low voltage side in the form of T access and JKLYJ-70 cables used in the main lines of the low voltage and circuits linked by the 
PV. In order to describe the influence of the distributed $\mathrm{PV}, 380 \mathrm{~V}$ distribution feeder is divided into 10 nodes by the distance between each other, and the power load is allotted to each node. The outlets of the low voltage busbar are ranked in an ascending order and the numbering starts at 0 . The circuit impedance between nodes $\mathrm{i}$ and $\mathrm{j}$ is $R_{i j}+j X_{i j}$, and the voltage of the low voltage busbar of the transformer is considered the baseline voltage and remains invariant.

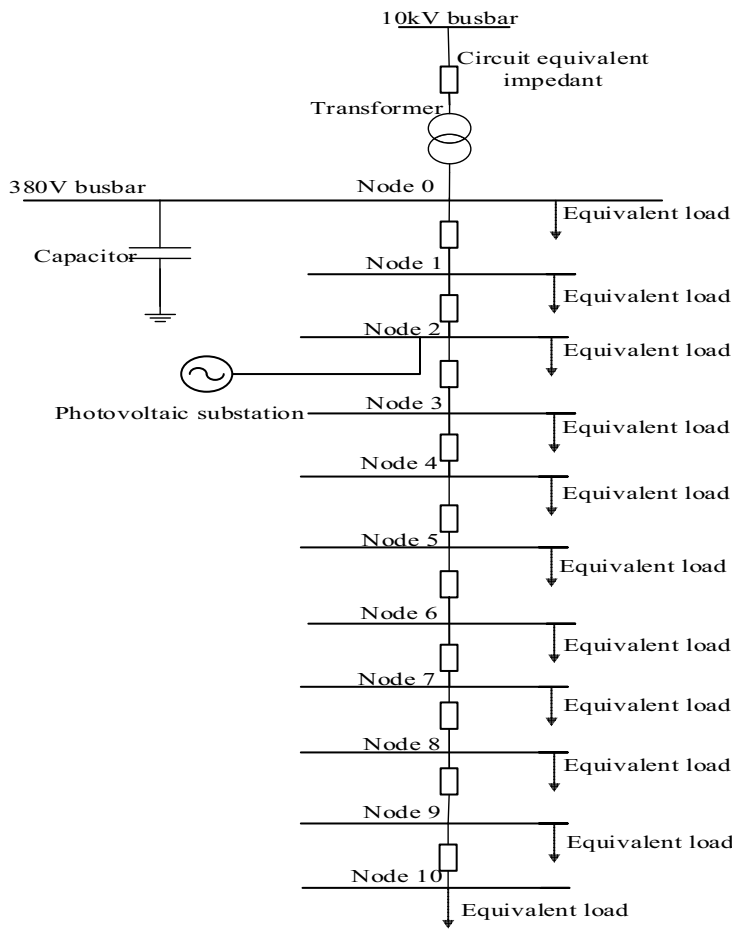

Figure 3. Feeder model of distribution networks

\subsection{Influence of the access capacity of the distributed PV on the voltage distribution}

The distributed PV is located at the node 5 of the distribution feeder and its power factor always remains 1 . The voltage distribution is shown in Fig.4, when the PV output reaches $80 \mathrm{~kW}, 100 \mathrm{~kW}$ and $120 \mathrm{~kW}$.

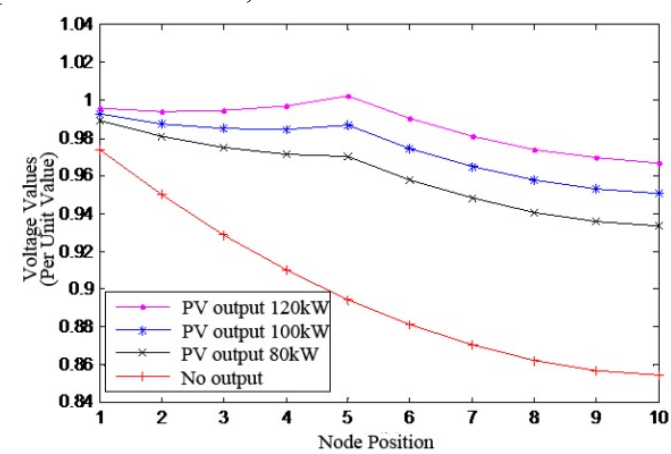

Figure 4. Distribution diagram of the feeder voltage under different access capacity

It is clear that the different capacities of the distributed PV in the same place have different effects for the voltage distribution of the feeder. The PV can contribute to the increase of the voltage of the load node. When the access capacity of the distributed PV is within a given range, the effect of the access point is much clear. If the PV is over a special range, the voltage can be beyond limits.

\subsection{Influence of the access point of the distributed PV on the voltage distribution}

Firstly the access capacity is set to be $100 \mathrm{~kW}$ and power factor is set to be 1 . And then the experiment changes the access point of the PV in the distribution feeder. Some representative locations of the feeder are chosen. For example, node 1 is located at the head of the feeder. Node 5 is located in the middle of the feeder and node 10 is located at the bottom. Experimental results are shown in Fig.5.

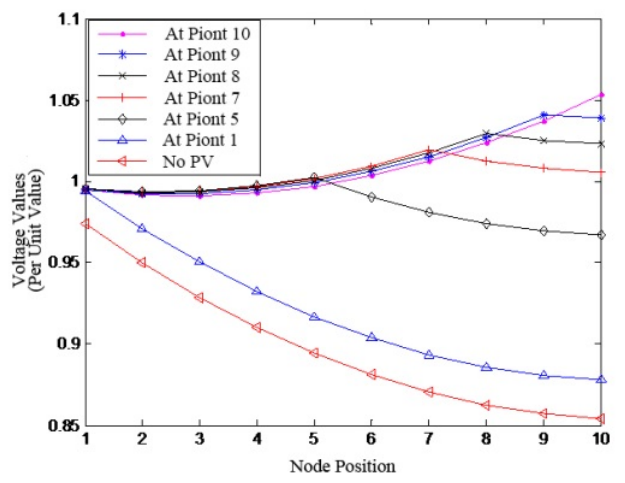

Figure 5. Distribution diagram of the feeder voltage under different access locations

According to the voltage distribution of the distribution feeder in Fig.5, there are different effects when the PV generations with the same capacity are linked to different locations. There is a little impact on the voltage of the feeder if the distributed PV is close to the equivalent power source and vice versa. When the PV with the high access capacity connects the node located at the bottom, the voltage of the node may be beyond limits. For example, the agriculture suffers from the influence of node 10 . Given the reduction of the voltage variant, the PV in the form of $\mathrm{T}$ access is not suitable for the bottom of the distribution network. But the PV is obviously suitable for the middle of the distribution network. For example, nodes 7, 8 and 9 not only play the role of the voltage support, but also avoid the problem of beyond limits. Hence, the PV in the form of $\mathrm{T}$ access is fit for the middle of the feeder.

\subsection{Influence of the power factor of the distributed PV on the voltage distribution}

First the output of the PV substation is set to be $100 \mathrm{~kW}$ and access point is fixed at node 5. And then the experiment changes the power factor of the PV. The voltage distribution is shown in Fig.6. 


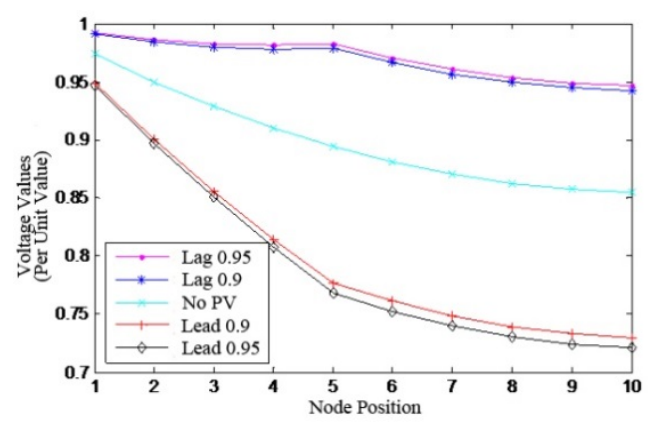

Figure 6. Distribution diagram of the feeder voltage under different power factor

Based on the voltage distribution, the voltage of the distribution network with the grid-connected PV is increased due to the lagging power factor. If the power factor is high, the effect is more clearly. Oppositely, the $\mathrm{PV}$ with the leading power factor aggravates the problem for the low voltage in rural distribution networks, which is equal to appending a load. Hence, the PV with the lagging

\section{Conclusion}

As for the PV poverty alleviation project, the influence on the voltage distribution in the distribution network with the grid-connected distributed PV is analysed. The distributed $\mathrm{PV}$ in the form of $\mathrm{T}$ access is incorporated into the $380 \mathrm{~V} / 220 \mathrm{~V}$ low voltage power grid and the related model is constructed. Based on the pilot project, the influence of the access capacity, access position and power factor on the voltage distribution is analysed by comparing the voltage changes before and after incorporating the PV into the distribution network. The paper provides the important theoretical support for the PV poverty alleviation project.

\section{References}

1. Yu J C, Chi F J, Xu K, Li S W, Liu H, Li H Y, Li D. Analysis of the Impact of Distributed Generation on Power Grid. Proceedings of the Chinese Society of Universities. 2012, 24 (1) : 138-141.

2. Liu W, Peng D, Bu G Q, Su J. A Survey on System Problems in Smart Distribution Network with GridConnected Photovoltaic Generation. Power System Technology, 2009, 33(19): 1-6

3. Kou F H. Impacts of Distributed Photovoltaic Power Sources on Distribution Network Loss. Advances of Power System \& Hydroelectric Engineering, 2011, 27(11): 62-68

4. Li T Y, Han Y Q, Hu X Q, Pan Z, Zhou N C. Characteristics of Static Voltage Stability for Distributed Generation Integrated into Power System and Its Impacts Analysis. Power System Protection and Control, 2014, 42(12): 8-13

5. Chen H Y, Duan X Z. Chen J F. Distributed Generation Planning Model and Algorithm Considering Static Voltage Stability Constrain in
Distribution Network. Power System Technology, 2006, 30(21): 11-14

6. Chen Q N, Wei G,Wu W L, Zhang X. The Impact of Distribution Characteristics of Distributed Generation on Voltage Quality of Micro-grid. Modern Electric Power, 2013, 30(6): 32-37.

7. Choi J H, Kim J C. Advanced voltage regulation method of power distribution system interconnected with dispersed storage and generation systems. IEEE Trans on Power Delivery, 2001, 16(2):329-334

8. Xu X Y, Huang Y H, Liu C, Wang W S. Influence of Distributed Photovoltaic Generation on Voltage in Distribution Network and Solution of Voltage Beyond Limits. Power System Technology, 2010, 34(10): $140-146$

9. Liu J, Zhang Z H, Huang W, Wei H K. Influence of Distributed Generation on Fault Location and Voltage Quality of Distribution Network. Electric Power Construction, 2015, 36(1): 115-121.

10. Wang Z Q, Zhu S Z, Zhou S X, Huang Y L, Wang L G. Impacts of Distributed Generation on Distribution System Voltage Profile. Automation of Electric Power Systems. 2004, 28(16): 56-60

11. Pei X J. Impact of Distributed Generation on the change of Voltage of Distribution System. ChengDu, Southwest Jiaotong University, 2011.

12. Pei , Sheng K, Kong L, Qi Z P. Impact and Improvement of Distributed Generation on Distribution Network Voltage Quality, Proceedings of the Chinese Society for Electrical Engineering, 2008, 28(13): 152-157

13. Yao D. Optimal Allocation of Distributed Generation and Its Effect on Power Quality. Shanghai, Shang Hai Jiao Tong University, 2015 